\title{
The Effects of Different Variables on Marginal Bone Loss around Dental Implants BK Orhan ${ }^{1}$, G Sonmez ${ }^{2}$, MO Ozemre ${ }^{1}$, C Koseoglu Secgin ${ }^{1}$, K Kamburoğlu ${ }^{2}$, A Gulsahi ${ }^{1}$
}

\begin{abstract}
Objective: To assess the effects of different variables including implant type and thread design, bone width and height measured on cone beam computed tomography (CBCT) images, along with systemic and patient related factors on marginal bone loss around dental implants which were measured on postoperative panoramic radiographs.
\end{abstract}

Methods: A total of 116 dental implants from two manufacturers were used in the study. Age, gender, history of diabetes mellitus and hypertension, smoking habit, implant thread type, implant site, length and diameter were recorded. Available alveolar bone width and height were measured on preoperative CBCT images. Marginal bone loss around dental implants was measured on the panoramic radiographs taken three months after implant placement on both mesial and distal sides.

Results: There were no statistically significant differences for the measurements of marginal bone loss on both distal and mesial sides according to gender, region, jaw and implant type. While there was a significant difference between patients with and without diabetes mellitus in terms of distal marginal bone loss $(p<0.05)$; no significant difference was found between patients with and without diabetes mellitus for mesial marginal bone loss. The mean of marginal bone loss was $1.43 \pm 0.75 \mathrm{~mm}$ and $1.45 \pm 0.75$ at the distal and mesial sides, respectively. We found statistically significant differences for alveolar width and marginal bone loss. However, no significant differences were found for the height measurements.

Conclusion: Marginal bone loss increased with an increase in bone width. There were no significant differences for the measurements of marginal bone loss on both distal and mesial sides according to gender, region, jaw, and implant tỳpe.

Keywords: Bone loss, cone beam computed tomography, dental implants, panoramic radiography

From ${ }^{1}$ Department of Dentomaxillofacial Radiology, Faculty of Dentistry, Başkent University, Ankara, Turkey and ${ }^{2}$ Department of Dentomaxillofacial Radiology, Faculty of Dentistry, Ankara University, Ankara, Turkey.

Correspondence: Dr MO Ozemre, Dentomaxillofacial Radiology, Faculty of Dentistry, Baskent University 82. sokak No: 26 Bahcelievler, Cankaya, Ankara, Turkey. Tel: 0090312203 00 05/1609.

Email: mehmetozgurozemre@yahoo.com 


\section{INTRODUCTION}

Cone beam computed tomography (CBCT) systems operate by focusing a cone-shaped beam on a two-dimensional detector that performs one pass or less around the patient's head to produce a series of 2-D images. The use of special algorithms allows conventional axial plane reconstructions, along with multi-planar, reformatted 2-D, 3-D and panoramic reconstructions which can be utilized for dental implant planning and placement $(1-3)$. Cone beam computed tomography has largely replaced medical multislice tomography for most dental diagnostic tasks and is now commonly used for a variety of purposes in oral implantology. Cone beam computed tomography images were found to be successful when used for linear measurement of implant sites. Cone beam computed tomography has also been shown to provide reliable 3-D information for the assessment of relative bone quality and quantity, evaluation of ridge topography and identification of vital anatomical structures such as; the inferior alveolar nerve, mental foramen, incisive canal, maxillary sinus, ostium and nasal cavity floor $(4,5)$.

Information obtained from $\mathrm{CBCT}$ data can be used in the treatment planning process to identify appropriate implant sites and to determine whether or not there is a need for sinus lifting and bone augmentation $(4,5)$. Cone beam computed tomography should only be used if twodimensional techniques have been unsuccessful to assess bone-implant interface (4) and to identify peri-implant defects due to concerns over dose and metal artifacts caused by implants(6).

Successful dental implant placement requires long-term maintenance of the soft and hard tissue surrounding the implant. Until recently various parameters such as; mobility, pain, infection, inflammation and marginal bone levels were assessed as success criteria (7-9). Recently, authors proposed a new classification and assessed implant success according to three subtitles as follows: patient-reported outcome measures, implant-supported restoration 
and peri-implant health (10). Specific interest and attention was directed towards peri-implant health and radiographic measurement of marginal bone levels since amount of bone around implants may effect mechanical stability and dental esthetics (11). Radiography is of paramouth importance in monitoring changes in the amount of marginal bone surrounding the implant after implant insertion. Intraoral imaging provides the best spatial resolution of any imaging method currently available for the evaluation of marginal bone around implants. The clinical diagnostic capacity of intraoral radiography is influenced by a number of variables, including beam angulation, exposure time, receptor sensitivity, processing, viewing conditions, superimposition of anatomic structures and lesion location (12-15). In routine clinical practice panoramic radiography, which is able to provide broad coverage of both jaws and teeth, but without the anatomical detail available with intraoral radiography is frequently utilized for postoperative implant placement.

Vertical bone loss at the surfaces facing implants should not exceed 1-2 mm during the first year of function and $0.2 \mathrm{~mm}$, thereafter (16). A decrease in bone level indicates a loss in the implant's bony anchorage. In order to gain more insight into the factors affecting the marginal bone loss around dental implants, long-term clinical evaluation of dental implants and their superstructure is necessary. Therefore, the aim of this retrospective study was to assess the effects of different variables including implant type and thread design, bone width and bone height measured on CBCT images, along with systemic and patient related factors on marginal bone loss around dental implants which were measured on postoperative panoramic radiographs.

\section{MATERIALS AND METHODS}

After receiving local ethical approval, a total of 116 patients (56 women and 60 men) who had been placed 116 dental implants with pre-operative CBCTs and three months postoperative 
panoramic radiographs were evaluated retrospectively. All implants were placed according to manufacturer recommendations at a private clinic by an experienced surgeon with 20 years of experience by using two different dental implants with two different thread designs.

In this study, 116 dental implants were used from two manufacturers; 64 were MIS (MIS Implants Technologies Ltd., Shlomi, Israel) [diameter range, 3.5-5 mm; length range, 8-11.5 mm] and 52 were Oxy Implants (Biomec SRL, Colico, Italy) [diameter range, 3.5-5 $\mathrm{mm}$; length range, $8.5-13 \mathrm{~mm}$ ] with aggressive thread design. Age, gender, history of diabetes mellitus and hypertension, smoking habit, implant thread type (normal or aggressive), implant length, and implant diameter and implant site (maxilla or mandible, anterior or posterior) were recorded for each patient. In addition, measurements of available alveolar bone width and height were measured on cross-sectional preoperative CBCT images which were obtained by using Iluma CBCT Unit (IMTEC, Ardmore, OK, USA) and dedicated software. Prior to measurements section thickness and interval were set $0.1 \mathrm{~mm}$. Available alveoler width measurements were performed at coronal, middle and apical regions of alveoler bone. Available alveolar height measurements were performed from $1 \mathrm{~mm}$ below the top of alveolar crest to apical part of the alveolar bone (Fig. 1). In addition, marginal bone loss around dental implants was measured on the panoramic radiographs obtained with Planmeca Promax (Planmeca, Helsinki, Finland) at 54 kVp, $5 \mathrm{~mA}$ and 15.8 seconds. Three months after implant placement by using dedicated software. For each implant, postoperative measurements of marginal bone loss were performed on both mesial and distal point of the implant platform to the crestal bone. Calibration was performed using the known lengths of the inserted implants (Fig. 2). All CBCT and panoramic measurements were performed three times by a single observer an oral radiologist and average calculated. To assess intra observer agreement, the measurements were repeated by the same observer after two weeks. 
Orhan et al

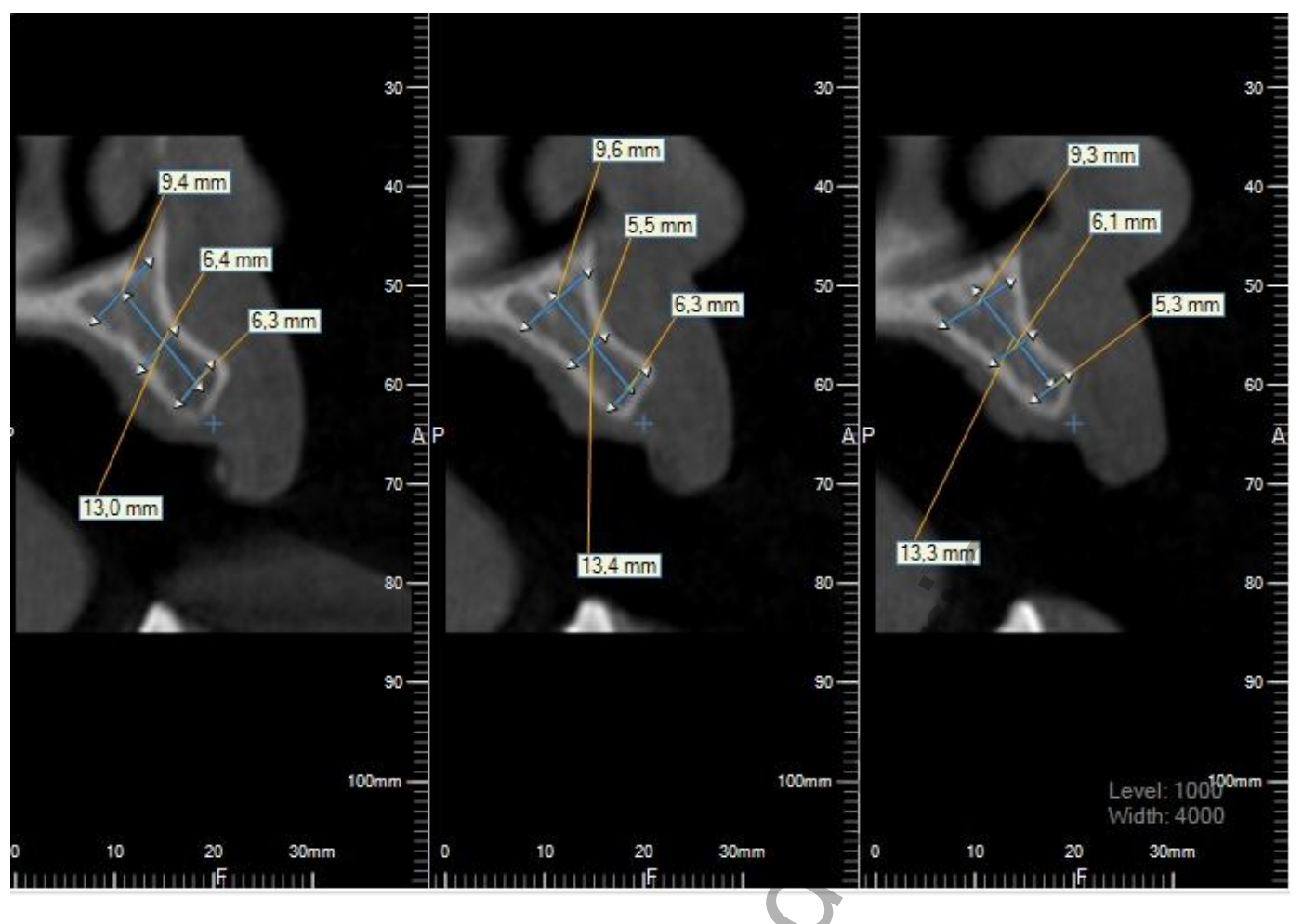

Fig. 1: Available alveolar height and width measurements from cone beam computed tomography images are shown.

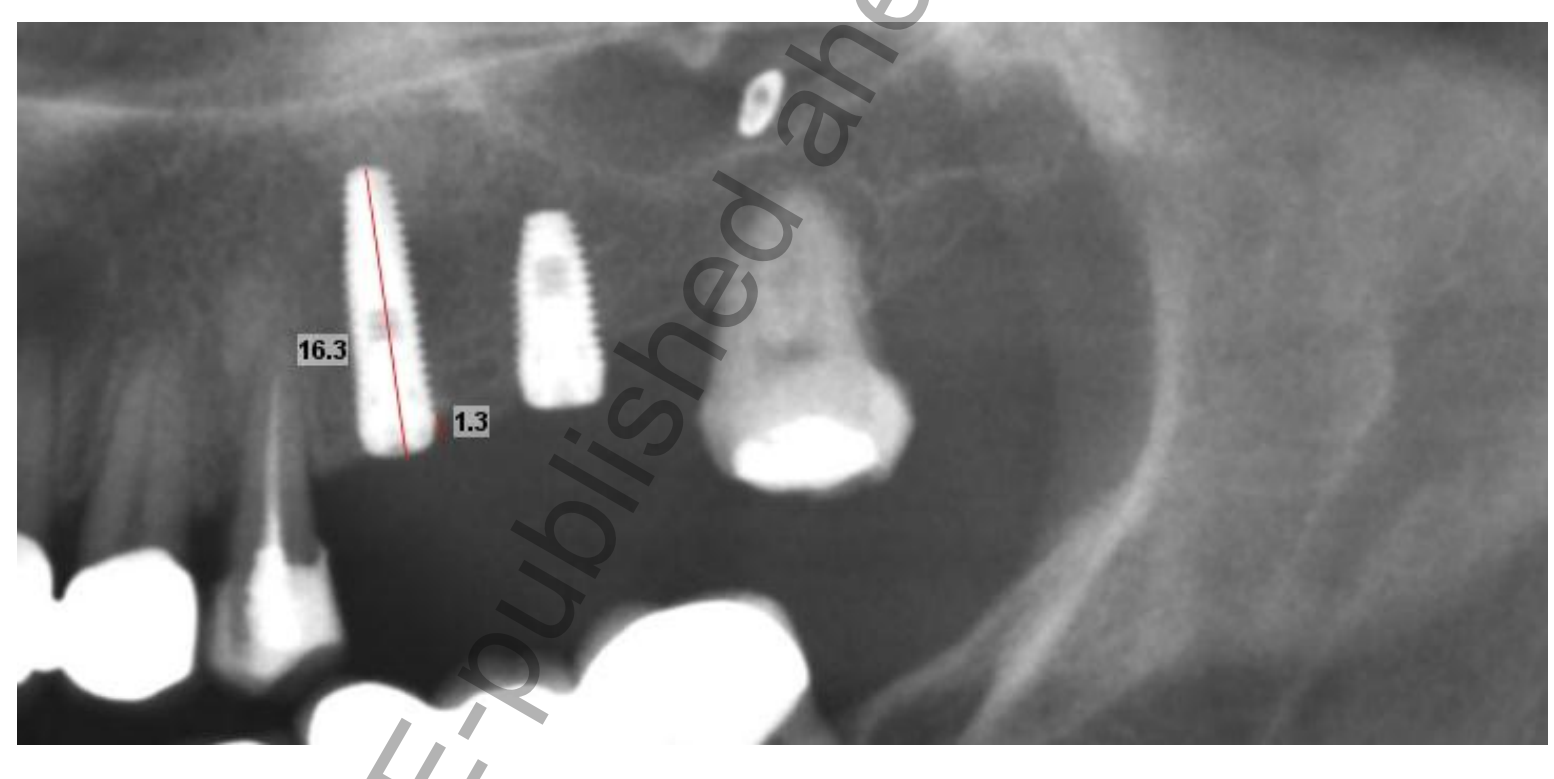

Fig. 2: Implant length measurement $(16.3 \mathrm{~mm})$ for calibration by using the known lengths of the inserted implant and marginal bone loss measurement $(1.3 \mathrm{~mm})$ from panoramic image. 
Descriptive statistics were performed. Comparison of distal and mesial measurements was conducted by using Mann-Whitney $U$ test and Kruskal-Wallis variance analysis. Pearson correlation was used to assess the relationship between implant site and bone loss.

Statistical significance was set $p<0.05$.

\section{RESULTS}

Table 1 shows the demographic information of the patients.

Table 1: The demographic information of the patients

\begin{tabular}{ll}
\hline TABLE 1 & $\mathbf{n}(\%)$ \\
\hline Gender & $56(48.3)$ \\
Female & $60(51.7)$ \\
Male & $62(53.4)$ \\
Implant Site & $54(46.6)$ \\
Right & $64(55.2)$ \\
Left & $52(44.8)$ \\
Jaw & \\
Maxilla & $50(43.1)$ \\
Mandible & $43(37.1)$ \\
Region & $23(19.8)$ \\
Molar & $52(44.8)$ \\
Premolar & $64(55.2)$ \\
Anterior & \\
Implant type & $102(87.9)$ \\
MIS & $14(12.1)$ \\
OXY & \\
Diabetes Mellitus & $109(94)$ \\
Present & $7(6)$ \\
Absent & \\
Hypertension & $37(31.9)$ \\
Present & $70(60.3)$ \\
Absent & $9(7.8)$ \\
Smoking Habits & \\
Non-smoker & \\
Half package per day & \\
One package per day & \\
\hline
\end{tabular}

Table 2 reveals mean, median, minimum and maximum values of distal and mesial marginal bone loss and their standard deviations in terms of gender, jaw and implant related factors. 
Orhan et al

There were no significant differences for the measurements of marginal bone loss on both distal and mesial sides according to gender, implant site, jaw, region and implant type $(p>0.05)$.

Table 2. The mean, median, mimimum and maximum values of distal and mesialmarginal bone loss and their standard deviations in terms of gender, jaw and implant related factors.

\begin{tabular}{|c|c|c|c|c|}
\hline \multirow{2}{*}{ Parameters } & \multirow{2}{*}{\multicolumn{2}{|c|}{$\begin{array}{c}\text { Marginal Bone Loss } \\
\text { Distal }\end{array}$}} & \multirow{2}{*}{\multicolumn{2}{|c|}{$\begin{array}{c}\text { Marginal Bone Loss } \\
\text { Mesial }\end{array}$}} \\
\hline & Mean+SD & & & \\
\hline \multicolumn{5}{|l|}{ Gender } \\
\hline Female & $1.49 \pm 0.76$ & $1.40(0.40-4.50)$ & $1.50 \pm 0.89$ & $1.20(0.37-50)$ \\
\hline Male & $1.20 \pm 0.63$ & $1.15(0.41-2.91)$ & $1.24 \pm 0.63$ & $1.11(0.45-2.73)$ \\
\hline $\begin{array}{l}\text { p } \\
\text { Implant Site }\end{array}$ & \multicolumn{2}{|c|}{0.075} & \multicolumn{2}{|c|}{ Implant Site } \\
\hline Right & $1.49 \pm 0.83$ & $1.23(0.40-4.50)$ & $1.49 \pm 0.89$ & $1.18(0.45-5.0)$ \\
\hline Left & $1.42 \pm 0.65$ & $1.25(0.41-3.89)$ & $1.40 \pm 0.80$ & $1.13(0.37-3.99)$ \\
\hline $\mathbf{p}$ & \multicolumn{2}{|c|}{0.586} & \multicolumn{2}{|c|}{0.725} \\
\hline \multicolumn{5}{|l|}{ Jaw } \\
\hline Maxilla & $1.34 \pm 0.69$ & $1.21(0.40-4.50)$ & \pm 0.85 & $1.15(0.37-4.20$ \\
\hline Mandible & $1.54 \pm 0.80$ & $1.54(0.43-3.89)$ & $1.50 \pm 0.86$ & $1.18(0.46-5.0)$ \\
\hline $\mathbf{p}$ & \multicolumn{2}{|c|}{0.165} & \multicolumn{2}{|c|}{0.449} \\
\hline \multicolumn{5}{|l|}{ Region } \\
\hline Molar & $1.41 \pm 0.83$ & $1.25(0.40-4.50)$ & $1.39 \pm 0.96$ & $1.10(0.46-5.0)$ \\
\hline Premolar & $1.42 \pm 0.64$ & $1.25(0.52-2.91)$ & $1.54 \pm 0.83$ & $1.27(0.37-3.99)$ \\
\hline Anterior & $1.48 \pm 0.78$ & $1.25(0.56-3.50)$ & $1.39 \pm 0.63$ & $1.20(0.48-2.91)$ \\
\hline $\mathbf{p}$ & \multicolumn{2}{|c|}{0.777} & \multicolumn{2}{|c|}{0.469} \\
\hline \multicolumn{5}{|l|}{ Implant Type } \\
\hline MIS & $1.56 \pm 0.94$ & $1.40(0.41-4.50)$ & $1.52 \pm 1.05$ & $1.10(0.37-5.0)$ \\
\hline OXY & $1.32 \pm 0.53$ & $18(0.40-2.53)$ & $1.38 \pm 0.65$ & $1.21(0.45-2.91)$ \\
\hline $\mathbf{p}$ & & & \multicolumn{2}{|c|}{0.931} \\
\hline
\end{tabular}

Table 3 shows the distal and mesial marginal bone loss according to diabetes mellitus, hypertension and smoking habits. There was a significant difference between patients with and without diabetes mellitus in terms of distal marginal bone loss $(p<0.05)$. However, we found no significant difference between patients with and without diabetes mellitus for mesial marginal bone loss $(p>0.05)$. In addition, no significant differences were found among patients with and without hypertension, patients with and without smoking habits according to both distal and mesial marginal bone loss. 
Table 3: The distal and mesial marginal bone loss according to diabetes mellitus, hypertension and smoking habits

\begin{tabular}{|c|c|c|c|c|}
\hline \multirow[t]{2}{*}{ Parameters } & \multicolumn{2}{|c|}{$\begin{array}{l}\text { Marginal Bone Loss } \\
\text { Distal }\end{array}$} & \multicolumn{2}{|c|}{$\begin{array}{c}\text { Marginal Bone Loss } \\
\text { Mesial }\end{array}$} \\
\hline & Mean \pm SD & Median (Min-max) & Mean $\pm S D$ & Median (Min-max) \\
\hline \multicolumn{5}{|l|}{ Diabetus Mellitus } \\
\hline Absent & $1.39 \pm 0.76$ & $1.22(0.40-4.50)$ & $1.40 \pm 0.79$ & $1.17(0.37-4.20)$ \\
\hline Present & $1.72 \pm 0.60$ & $1.80(0.77-3.20)$ & $1.77 \pm 1.16$ & $1.77(0.50-5.00)$ \\
\hline p & & 0.036 & & \\
\hline \multicolumn{5}{|l|}{ Hypertension } \\
\hline Absent & $1.41 \pm 0.71$ & $1.25(0.41-4.50)$ & $1.45 \pm 0.83$ & $1.17(0.37-5.00$ \\
\hline Present & $1.79 \pm 1.26$ & $1.38(0.40-3.50)$ & $1.40 \pm 1.17$ & $1.10(0.68-3.99)$ \\
\hline p & & 0.626 & & 0.543 \\
\hline \multicolumn{5}{|l|}{ Smoking Habits } \\
\hline Non smoker & $1.36 \pm 0.93$ & $1.12(0.40-4.50)$ & $1.29 \pm 0.88$ & $1.05(0.46-4.20)$ \\
\hline Half package perday & $1.48 \pm 0.63$ & $1.43(0.46-3.40)$ & $1.52 \pm 0.84$ & $1.22(0.37-5.00)$ \\
\hline One package perday & $1.30 \pm 0.77$ & $0.90(0.43-2.91)$ & $1.51 \pm 0.81$ & $1.27(0.59-2.82)$ \\
\hline p & & 0.145 & & 0.100 \\
\hline
\end{tabular}

The mean and standard deviation of marginal bone loss was $1.43 \pm 0.75$ and $1.45 \pm 0.85 \mathrm{~mm}$ at the distal and mesial sides, respectively. No significant difference was found between mesial and distal marginal bone loss.

Table 4 shows the alveolar width and height measurements in both mesial and distal sides. We found a positive correlation between alveolar width measurements (except mesial apical width) and marginal bone loss. However, no significant differences were found for the height measurements $(p>0.05)$.

Table 4: The alveolar width and height measurements in both mesial and distal sides

\begin{tabular}{lcccc}
\hline & \multicolumn{2}{c}{ Distal Side } & \multicolumn{2}{c}{ Mesial Side } \\
\hline Width (apical) & $\mathrm{r}$ & $\mathrm{p}$ & $\mathrm{r}$ & $\mathrm{p}$ \\
Width (middle) & 0.235 & 0.011 & 0.052 & 0.581 \\
Width (coronal) & 0.283 & 0.002 & 0.252 & 0.006 \\
Height & 0.213 & 0.022 & 0.235 & 0.011 \\
\hline
\end{tabular}

$p<0.05$ 


\section{DISCUSSION}

We assessed the effects of insertion site, implant type and thread design, bone width and bone height measured on CBCT images, along with gender and patient related factors on marginal bone loss around dental implants in the maxilla or in the mandible. Since clinical oral implant success requires maintenance of the immobility of individual implants, marginal bone loss around dental implant is among the most important factors for the assessment of treatment outcome (17). In this retrospective study, it was neither possible nor practical to determine the actual marginal alveolar bone loss at the distal and mesial sites. As a result, the diagnostic accuracy of the methods was not assessed and a gold standard was not established. We did not perform postoperative $\mathrm{CBCT}$ imaging as it is not the modality of choice for postoperative implant assessment due to radiation concerns and technical issues related to beam hardening artefacts. A drawback of panoramic radiography chosen for the present study was that a magnifying factor associated with image formation, and projection geometry results in image distortion and a marked overlapping of tooth crowns. Only one implant was choosen for each patient and calibration of panoramic images which are frequently utilizied for postoperative implant assessment was performed mathematically based on the known lengths of the implants.

A previous study found no significant difference for patients or for implants for the advanced surgery cases or the conventional approach in diabetic patients compared to non diabetic patients (18). The overall survival rate for the diabetic group was $97.2 \%$ (control 98.8\%) and was not significantly different for age, gender, diabetes duration, smoking, or type of hypoglycaemic therapy. The mean peri-implant bone loss was $0.41 \pm 0.58 \mathrm{~mm}$ (control, $0.49 \pm 0.64 \mathrm{~mm}$ ). Similarly, we found no statistically significant difference between patients with and without diabetes mellitus for marginal mesial bone loss $(p>0.05)$. In the present study, we did not assess information regarding the blood tests and related values of the 
patients and therefore our findings regarding diabetes mellitus were based on only patients' history. In addition we found no significant differences among patients with and without hypertension, patients with and without smoking habits and patients who were smokers and had hypertension, in terms of both distal and mesial marginal bone loss measurements.

A study found that the mean bone loss around implants was $0.553 \mathrm{~mm}$ on mesial aspect and $0.503 \mathrm{~mm}$ on distal aspect. The $p$-value for both mesial and distal aspect of implant was found to be statistically non-significant. The mean bone loss on mesial aspect of implants was $0.601 \mathrm{~mm}$ for maxillary implants and $0.473 \mathrm{~mm}$ form and ibular implants, whereas the mean bone loss on distal aspect of implants was $0.481 \mathrm{~mm}$ for maxillary implants and $0.541 \mathrm{~mm}$ for mandibular implants (19).The $p$-values for both mesial and the distal aspect of implant were found to be statistically non-significant analogous to our findings. In the present study, calculated mean and standard deviation measurements of marginal bone loss was $1.43 \pm 0.75$ and $1.45 \pm 0.85 \mathrm{~mm}$ at the distal and mesial sides three months after insertion. Higher bone loss found in our study might be due to the fact that we measured bone loss three months after implantation whereas in the mentioned study authors measured bone loss one year after implantation.

In the present study, only one experienced expert evaluated the images in order to eliminate observer bias. Howeyer, when a decision could not be made by the observer a second decision was made by another researcher. In a study that examined the accuracy and quality of both 2D and 3D measurement techniques, simulated peri-implant defects were measured using 2D intraoral radiography and panoramic radiography as well as 3D computerized tomography(CT) and digital volumetric tomography (20).With both CT and dental volumetric tomography scans, bone defects could be measured in all three planes and showed only slight mean deviations when compared with direct measurement $(\mathrm{CT}, 0.17 \pm 0.11 \mathrm{~mm}$; dental 
Orhan et al

volumetric tomography, $0.18 \pm 0.12 \mathrm{~mm}$ ). With intraoral radiographic and panoramic radiographic images, the defects could be detected in only themesiodistal and craniocaudal planes and showed greater mean deviations when compared with direct measurement (intraoral radiography, $0.34 \pm 0.30 \mathrm{~mm}$; panoramic radiography, $0.41 \pm 0.35 \mathrm{~mm}$ ).Although dental volumetric tomography provides images in three planes without distortion, it is not always appropriate or possible to use in routine clinical practice because of higher radiation doses when compared with intraoral radiography, as well as high costs and lack of availability (20).

We found that the increase in marginal bone loss overtime was found to be correlated with width on both sides, however; no correlation was found for height variable. Marginal bone loss increased with an increase in bone width. There were no statistically significant differences for the measurements of marginal bone loss on both distal and mesial sides according to gender, region, jaw and implant type. Further studies are essential to fully understand the parameters which may have an effect on marginal bone loss around implants.

\section{ACKNOWLEDGEMENTS}

There is no acknowledgements and financial supports.

\section{AUTHOR CONTRIBUTION}

MO Ozemre and BK Orhan participated in study design, data collection, data analysis and interpretation.G Sonmez and C Koseoglu Secginparticipated in data interpretation. K Kamburoglu and A Gulsahi oversight to study, participated in data interpretation and revision of manuscript, and approved final version. The authors declare that they have no conflicts of interest 


\section{REFERENCES}

1. White SC. Cone-beam imaging in dentistry. Health Physics 2008; 95: 628-637.

2. Scarfe WC, Farman AG, Levin MD, Gane D. Essentials of maxillofacial cone beam computed tomography. Alpha Omegan 2010;103: 62-67.

3. Scarfe WC, Farman AG. What is cone-beam CT and how does it work? Dent Clin North Am 2008;52(4):707-30.

4. Benavides E, Rios HF, Ganz SD, An CH, Resnik R, Reardon GT, Feldman SJ, Mah JK, Hatcher D, Kim MJ, Sohn DS, Palti A, Perel ML, Judy KW, Misch CE, Wang HL. Use of cone beam computed tomography in implant dentistry: The international congress of oral implantologists consensus report. Implant Dent2012;21(2):78-86.

5. Baciut M, Hedesiu M, Bran S, Jacobs R, Nackaerts O, Baciut G. Pre- and postoperative assessment of sinus grafting procedures using cone-beam computed tomography compared with panoramic radiographs. Clin Oral Implants Res 2013;24(5):512-6.

6. Mengel R, Kruse B, Flores de Jacoby L. Digital volume tomography in the diagnosis of peri-implant defects: an in vitro study on native pig mandibles. J Periodontol 2006;77:123441.

7. Jones AA, Cochran DL. Consequences of implant design. Dent Clin North Am 2006;50:339-60.

8. Mombelli A, Lang NP. Clinical parameters for the evaluation of dental implants. Periodontol 20001994;4:81-86.

9. Chung WE, Rubenstein JE, Phillips KM, Raigrodski AJ. Outcomes assessment of patients treated with osseointegrated dental implants at the University of Washington Graduate Prosthodontic Program, 1988 to 2000.Int J Oral Maxillofac Implants 2009;24(5):927-35. 
Orhan et al

10. Tonetti M, Palmer R; Working Group 2 of the VIII European Workshop on Periodontology.Clinical research in implant dentistry: study design, reporting and outcome measurements: consensus report of Working Group 2 of the VIII European Workshop on Periodontology.J Clin Periodontol 2012;39(supply 12):73-80.

11. Nisapakultorn K, Suphanantachat S, Silkosessak O, Rattanamongkolgul S. Factors affecting soft tissue level around anteriormaxillary single-tooth implants.Clin Oral Implant Res2010;21(6):662-70

12. Kamburoğlu K, Barenboim SF, Kaffe I. Comparison of conventional film with different digital and digitally filtered images in the detection of simulated internal resorption cavitiesan ex vivo study in human cadaver jaws. Oral Surg Oral Med Oral Pathol Oral Radiol Endod 2008;105:790-97.

13. Kamburoğlu K, Tsesis I, Kfir A, Kaffe I. Diagnosis of artificially induced external root resorption using conventional intraoral film radiography, CCD, and PSP: an ex vivo study. Oral Surg Oral Med Oral Pathol Oral Radiol Endod 2008;106:885-91.

14. Kamburoğlu K, Cebeci AR, Gröndahl HG. Effectiveness of limited cone-beam computed tomography in the detection of horizontal root fracture. Dent Traumatol2009;25:256-61.

15. Tsesis I, Kamburoğlu K, Katz A, Tamse A, Kaffe I, Kfir A. Comparison of digital with conventional radiography in detection of vertical root fractures in endodontically treated maxillary premolars: an ex vivo study. Oral Surg Oral Med Oral Pathol Oral Radiol Endod2008;106:124-28.

16. Smith DE, Zarb GA. Criteria for success of osseointegrated endosseous implants. J Prosthet Dent 1989;62:567-72.

17. Zarb GA, Albrektsson T. Consensus report: towards optimized treatment outcomes for dental implants. J Prosthet Dent 1998;80(6):641. 
18. Tawil G, Younan R, Azar P, Sleilati G. Conventional and advancedimplanttreatment in the type II diabetic patient: surgical protocol and long-term clinical results. Int J Oral Maxillofac Implants 2008;23(4):744-52.

19. Nandal S, Ghalaut P, Shekhawat H.A radiologicalevaluation of marginalbonearounddentalimplants: An in-vivostudy. Natl J Maxillofac Surg 2014;5(2):126-37.

20. Mengel R, Kruse B, Flores-de-Jacoby L. Digital volume tomography in the diagnosis of peri-implant defects: an in vitro study on native pig mandibles. J Periodontol 2006;77:1234-41. 